\title{
OS ESTUDOS FONÉTICO-FONOLÓGICOS NOS ESTADOS DA PARAÍBA E DO CEARÁ
}

\author{
Maria do Socorro Silva de ARAGÃO \\ Universidade Federal do Ceará (UFC) \\ Universidade Federal de Pernambuco (UFPE) \\ Projeto Atlas Linguístico do Brasil (ALiB)
}

\section{RESUMO}

Neste trabalho analisaremos as diferenças diatópicas, marcas do falar da Paraíba e do Ceará, quanto aos fenômenos da despalatalização, iotização e apagamento dos fonemas / $\mathrm{K} /$ $e / \mathrm{n} /$, bem como da ditongação e monotongação, mostrando exemplos desses aspectos nos corpora analisados.

\section{ABSTRACT}

In this work we will analyze the diatopic differences, that mark Paraiba and Ceara dialects, in the aspects of depalatalization, iotization and disappearance of the phonemes $/ \mathrm{K} / \mathrm{e}$ $/ \mathrm{n} /$, as well as the diphthongization and monophthongization, showing examples of these aspects in the corpora analyzed.

\section{PALAVRAS-CHAVE}

Estudos fonético-fonológicos. Falar da Paraíba e do Ceará. Despalatalização, iotização e apagamento de fonemas. Ditongação e monotongação.

\section{KEY WORDS}

Studies inphonetics andphonology. The speech of Paraíba and Ceará States. Depalatalization, itozation and disappearance of the phonemes. Diphthongization and monophthongization. 


\section{Introdução}

Estudar os falares regionais nordestinos, sob o aspecto fonéticofonológico, tem sido, desde alguns anos atrás, nossa principal preocupação. Tal escolha não se deve, apenas, à nossa origem, mas também ao desejo de descobrir se as variações da língua portuguesa falada no nordeste são realmente regionais - diatópicas - hipótese esta sempre aventada pelos estudiosos do assunto, ou se são muito mais sociais - diastráticas, não marcando, assim, uma região, mas uma classe social, a dos menos escolarizados.

Pois, muitas vezes concordamos com Teyssier quando ele afirma:

[...] na realidade as divisões 'dialetais' são no Brasil menos geográficas que socioculturais. As diferenças nos modos de falar são maiores, num determinado lugar, entre um homem cultivado e seus vizinhos analfabetos que entre dois brasileiros do mesmo nível cultural originários de duas regiões distantes uma da outra. A dialetologia deve ser menos horizontal que vertical. (TEYSSIER, 1980:100)

O português falado no Ceará e na Paraíba vem sendo analisado não só por especialistas nordestinos, como, também, por pesquisadores de outras regiões que chegaram ao nordeste com o propósito de dar continuidade a esses estudos. Tais trabalhos seguem uma longa tradição de professores e estudiosos da área de letras, todos com o objetivo dos mais proveitosos, de coletar dados e informações para a análise dos falares cearense e paraibano nos seus aspectos fonético-fonológicos.

A pesquisa para o Atlas Linguístico do Brasil - Projeto AliB, no Estado do Ceará - AliB-CE e na Paraíba - ALiB-PB, nos inquéritos experimentais realizados em Fortaleza e João Pessoa, vem confirmando uma série de fatos fonético-fonológicos já detectados em trabalhos anteriores, realizados por nós e por outros pesquisadores locais e nacionais, com corpora diferentes. As pesquisas estão ainda em fase preliminar e somente com o desenvolvimento dos inquéritos os fatos encontrados e aqui 
analisados poderão ser confirmados, caracterizando, ou não, variantes regionais dos falares cearense e paraibano.

Neste trabalho analisaremos as diferenças diatópicas, marcas do falar do Ceará, representado pela capital, Fortaleza e da Paraíba, representado pela capital, João Pessoa, quanto aos fenômenos da despalatalização, iotização e apagamento dos fonemas $/ K / \mathrm{e} / \mathrm{n} /$; e a ditongação e monotongação, mostrando exemplos desses fenômenos nos corpora analisados.

\section{Os estudos fonético-fonológicos nos estados da Paraíba e do Ceará}

Os estudos fonético-fonológicos na região nordestina, até a segunda metade dos anos sessenta e início dos anos setenta, são poucos e em grande parte levados a efeito sem objetivos específicos bem definidos e metodologia adequada.

Muitos trabalhos, além de imprecisos quanto à delimitação do corpus, apresentam problemas metodológicos relativos à própria análise do material coletado.

Sob o aspecto fonético-fonológico, por exemplo, não foram estabelecidas as variantes de cada sub-região, e suas motivações diatópicas, diastráticas ou diafásicas. Vale ressaltar que os primeiros trabalhos, de modo geral, focalizaram mais o aspecto diacrônico, registrando-se apenas as alterações fonéticas sofridas pela língua, sem maiores análises ou explicações para as causas dessas mudanças.

Isto não quer dizer, entretanto, que todos os trabalhos até então efetuados no Nordeste pequem por absoluta ausência de rigor científico. Há trabalhos realizados com base em pesquisa de campo, com corpora bem delimitados, em que são considerados não só os aspectos puramente linguísticos, mas, também, os aspectos sócio e etnolinguísticos.

Outro problema quanto aos trabalhos realizados no Nordeste é sua pouca divulgação. Muitas vezes, são conhecidos apenas na instituição onde são realizados, não passando, sequer, para outras instituições do mesmo Estado. 
Contudo, felizmente, a partir de meados dos anos sessenta, com a obrigatoriedade da disciplina Linguística nos cursos de Letras e, na década de setenta, com o surgimento dos cursos de Pós-Graduação em Letras em nossa região, essa situação vem mudando radicalmente, como veremos a seguir.

Com a criação dos Mestrados e a exigência cada vez maior do MEC para que as instituições qualificassem seus professores, foram sendo implantados e fortalecidos cursos de Pós-Graduação em quase todo o Nordeste e mesmo aquelas Universidades que não têm cursos stricto sensu, já possuem seus cursos lato sensu, que têm preparado, com bastante eficiência, pessoal para concorrer ao Mestrado não só no Nordeste, mas no Sul e Sudeste.

Porém, a grande revolução desencadeada pelos cursos de PósGraduação no Nordeste foi a criação de Grupos de Pesquisa e, como consequência, o grande número de trabalhos apresentados em Encontros nacionais e estrangeiros, publicados por pesquisadores nordestinos, embora em comparação com o Sul e Sudeste estejamos em minoria, pelos motivos político-acadêmicos que todos conhecemos e que não vale a pena explicitar.

No estado da Paraíba os estudos fonético-fonológicos surgiram na década de 70 com as teses e dissertações de professores paraibanos que se qualificaram em outras regiões do país e com as dissertações surgidas no curso de Pós-Graduação em Letras da Universidade Federal da Paraíba. Tais professores e pesquisadores a partir daí constituíram seus próprios grupos de pesquisa, que vêm desenvolvendo excelentes trabalhos no campo da fonética e da fonologia.

Vale destacar, neste aspecto, os trabalhos desenvolvidos a partir das pesquisas para a elaboração do "Atlas Linguístico da Paraíba", publicado na década de 80 , sob nossa coordenação, que continuam a tradição paraibana de trabalhos de Fonética e Fonologia em toda a região.

Ainda na Paraíba, lembramos os trabalhos realizados pela equipe do Projeto "Variação Linguística no Estado da Paraíba" - VALPB, que vem 
apresentando sistematicamente os resultados dessa pesquisa.

No Ceará, temos, dos pesquisadores mais antigos, as contribuições de Martins de Aguiar, com seu trabalho "Fonética do Português do Ceará", Antônio Sales, com "O Falar Cearense", Florival Serraine, com vários trabalhos sobre a linguagem regional popular e José Rebouças Macambira, linguista cearense que estudou o falar cearense sob vários aspectos.

Atualmente, projetos como o do Atlas Linguístico do Brasil - AliBCE, o Atlas Linguístico do Ceará, o da Norma Urbana Culta de Fortaleza, o do Português Não-Padrão do Ceará, o dos Dialetos Sociais Cearenses e o de Variação e Processamento da Fala e do Discurso: Análises e Aplicações - Profala, entre outros e as novas Dissertações de Mestrado e Teses de Doutorado de professores e alunos das Universidades Federal e Estadual do Ceará, têm estudado aspectos específicos do falar cearense, sob a ótica da fonética e da fonologia do português culto e do português popular do Ceará utilizando as mais diferentes correntes da linguística moderna.

\section{Os corpora analisados}

Para a presente análise utilizamos inquéritos experimentais dos Questionários Fonético-Fonológico e Semântico-Lexical feitos para o Atlas Linguístico do Brasil, nas cidades de João Pessoa e Fortaleza, com quatro informantes, em cada uma delas, com as seguintes características:

a) homens e mulheres;

b) de duas faixas etárias: 18 a 30 e 45 a 60 anos;

c) de escolaridade até a 8 série do fundamental;

d) nascidos nas localidades em estudo. 


\section{Alguns aspectos analisados}

\subsection{Despalatalização e iotização dos fonemas $/ K / \mathrm{e} / \mathrm{n} /$}

O fonema $/ \Lambda$ / é descrito fonética e fonologicamente como consoante oral, sonora, lateral, dorso-palatal e o fonema / $/ \mathrm{h}$ como consoante vibrante, sonora, nasal, dorso-velar. Ambos ocorrem sempre em posição medial de sílaba medial, ou final de palavras e, com raríssimas exceções, em posição inicial de alguns empréstimos espanhóis e no pronome de

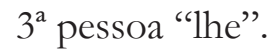

Ao tratar da posição das consoantes $/ \Lambda /$ e $/ \mathrm{n} /$ nas palavras, Câmara Jr. (1972: 38) considera uma neutralização a posição não-intervocálica de $/ 1-K / \mathrm{e} / \mathrm{n}-\mathrm{n} /$. Em suas palavras:

Podemos dizer que em posição não-intervocálica há uma neutralização das oposições entre [...] líquida dental /l/ e líquida palatal, ou molhada $/ \kappa /$, e entre nasal dental $/ \mathrm{n} / \mathrm{e}$ nasal palatal, ou molhada $/ \mathrm{n} /$, em proveito do primeiro membro de cada par.

Em determinados contextos, por facilidade ou relaxamento de articulação o $/ \kappa /$ e o $/ \mathrm{h} /$ podem perder o traço palatal, passando a ser articulados como alveolares /l/ e /n/, como iode /y/ ou sofrer apagamento, desaparecendo.

Autores há que consideram esse fato um fenômeno fonético. Outros acham que é um problema de influência africana, uma mudança fonética do latim para o português, ou ainda um fato que pode vir a ser fonológico, gerando um novo fonema e não apenas uma articulação diferente dos fonemas $/ \Lambda / \mathrm{e} / \mathrm{n} /$.

A despalatalização, definida como perda de traço palatal na articulação de um fonema, pode ser vista também como variedade regional, social, estilística ou individual.

Bergo (1986: 70) ao falar sobre o assunto diz que é: 
Fenômeno fonético de caráter individual ou regional, que consiste em trocar-se um fonema palatal por um alveolar ou linguodental em consequência de não se apoiar devidamente a ponta da língua na abóbada palatina ao proferir aquele som.

Jota (1976: 103) além de considerá-lo fato fonético, considera-o fato estilístico quando diz:

[...] O fato não é raro em linguagem descuidada de alguns, que mudam o $\mathrm{NH}$ ou $\mathrm{LH}$ por $\mathrm{N}$ ou L ... e ainda regional quando afirma: ... Em camadas rurais é comum [véyu] (velho), [muyé] (mulher)...

Ao falar da iodização/iotização como um dos fatos decorrentes da despalatalização, explica Jota (1976:179) que ela precede a palatalização na passagem do latim para o português, dizendo: "A iodização precede a palatalização: lat. milia > milya > milha[...]"

O autor (1976: 179) igualmente trata como ipsilonismo a passagem do / 1 / palatal - / $/$, em semiconsoante /y/ afirmando que "[...] $\mathrm{Na}$ passagem do latim para o port. ocorre na fase intermediária, anterior à palatalização: palia > palya > palha".

Já Melo (1981) considera a despalatalização um caso sociolinguístico, de registro de linguagem popular, de pessoas incultas, ao dizer:

Penso que a despalatalização seja fenômeno semi-culto, pois, muita vez, se ouve ligeira prolação do R final: mulér. Já a iotização (fio por filho) é fenômeno popular, em qualquer região do país.

Para Câmara Jr. (1979) a despalatalização pode muitas vezes, ser um fato fonológico, já que podemos ter mudança de significado do signo, tanto no caso de despalatalização $/ \Lambda>1 /$ como com a iotização $/ \Lambda>$ y/, como diz ele: 
[...] no caso do molhamento, trata-se a rigor de uma iotização, mas temos que considerar o resultado uma consoante simples em virtude da possibilidade de contraste como olhos-óleos, venha-vênia.

Mas ao definir a iotização o autor usa critérios fonéticos quando diz (1977: 149): "Mudança de uma vogal ou consoante para a vogal anterior alta /i/ ou para a semivogal correspondente ou iode".

Outra hipótese para a despalatalização e iotização do $/ \Lambda /$ e do $/ \mathrm{n} /$ é a da influência do português crioulo dos escravos ou do substrato indígena, como diz Câmara Jr. (1979): "É igualmente possível que [...] se explique pelo português crioulo dos escravos negros ou pelo substrato indígena [...]", hipótese esta também levantada por outros estudiosos que vêem a despalatalização e iotização como uma marca da fala dos índios e africanos que tinham dificuldades de articular o $/ \Lambda / \mathrm{e} \mathrm{o} / \mathrm{n} /$, como frisa Silva Neto (1977): “[...] No nosso caso particular e histórico, observamos que os aloglotas (mouros, índios e negros) se mostraram sempre incapazes de pronunciar o lh".

Historicamente pode-se também explicar o fenômeno uma vez que na passagem do latim para o português a iotização antecede a palatalização. Assim, em latim havia o iode, que se palataliza no português como nos casos de milia $>$ milya $>$ milha ou foleam $>$ folha ou somnium $>$ sonho, sendo que $/ 1+y / \operatorname{deram} / \kappa /$ e $/ \mathrm{n}+\mathrm{y} / \operatorname{deram} / \mathrm{n} /$.

Ora, no caso da despalatalização, que leva à iotização, o movimento se inverteu, ou seja, o / $/$ / desdobra-se em $1+y /$ e o /n/ em /n + y/.

Ao estudar a despalatalização e iotização do $[\Lambda>y]$ em Belo Horizonte, Minas Gerais, Madureira (1997: 6) confirma que a tendência em termos de Brasil é considerar o fenômeno "[...] como um processo que evidencia variação regional e social".

Uma visão nova desse fato surge a partir do modelo de Difusão Lexical que diz que "[...] a mudança linguística é lexicalmente gradual e foneticamente abrupta [...]”. Madureira (1997:14). 
A partir desse modelo e analisando dois itens lexicais trabalhar e velho, chega Madureira (1997: 17-18), à conclusão que:

[...] toda variação fonológica tem sua origem na expansão do sentido de um item lexical, o que se realiza através de alteração na realização de um fonema, constituindo-se essa alteração em uma marca.

ou seja, para ela "[...] a mudança fonológica tem por elemento desencadeador uma alteração de sentido que afeta um segmento de determinado item lexical [...]" (Madureira (1997: 19).

Quanto ao apagamento do $/ \kappa>\varnothing / \mathrm{e} / \mathrm{n}>\varnothing /$ os autores não têm dado muita ênfase, com exceção de Aguilera (1994), que registra o fato no falar do Paraná, porém com ocorrência mínima, a não ser em palavras específicas como "silhão" e "trilho".

\subsubsection{A despalatalização em Fortaleza e em João Pessoa}

Alguns trabalhos já foram realizados sobre a despalatalização, iotização e apagamento das consoantes palatais $/ \kappa / \mathrm{e} / \mathrm{n} /$, na cidade de Fortaleza. Aragão (1996) e Seraine (1985), utilizando o corpus da pesquisa Dialetos Sociais Cearenses e de João Pessoa, Aragão (1994) usando o corpus do Atlas Linguístico da Paraíba. Comparando-os com trabalhos semelhantes feitos com falares de outras regiões do país, eles mostraram que o fenômeno ocorre nas mais diversas regiões, configurando-se, o fato, não em uma variante regional, diatópica, mas uma variação social, diastrática, ligada ao grau de escolaridade dos informantes.

Nosso objetivo ao estudar o fenômeno no falar de Fortaleza e de João Pessoa é o de descrever e analisar a realização do $/ \kappa /$ e do $/ \mathrm{n} /$, observar a despalatalização, iotização e apagamento relacionados aos contextos linguísticos, aos contextos sociolinguísticos e aos contextos locais e regionais.

As primeiras análises indicam alguns fatos como os mostrados a seguir: 


\subsubsection{Apagamento do $/ \mathrm{n} />/ \varnothing /$}

Nos corpora estudados há uma predominância, quase que absoluta, do apagamento do /n/ > /ø/ antecedido da vogal fechada /i/, em sílaba nasal restando, contudo, a nasalização, como nos casos de:

“minha” ['mĩna > mĩøa] "caminho" [kã'mĩnu > kã'mĩøu] "lagoinha" [lagoĩna $>$ lagoñøa] e tantos outros casos.

\subsubsection{Permanência do $/ \Lambda /$}

Fato marcante, também nesse contexto, é a permanência do $/ \Lambda /$ tanto em sílaba medial quanto em final, como nos exemplos "milho"

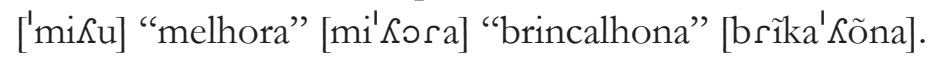

\subsubsection{Permanência do /n/}

O fonema $/ \mathrm{n} /$, permanece em sílaba medial e final, como nos exemplos "escolinha” [isko'lĩna] "conheço” [kũ̃'nesu] "sonhado” [sõ'nadu].

\subsubsection{Iotização do $/ \Lambda /$}

Em seguida, em número de ocorrências, vem a iotização do $/ \Lambda /$, em sílabas medial e final, como nos exemplos "filho" ['fiKu > 'fiyu] "milha" ['miKa > 'miya] "trabalhador" [trabaKa'doh > trabaya'do]

\subsubsection{Iotização do / $\mathrm{n} /$}

$\mathrm{O} / \varnothing /$ também sofre iotização em sílabas medial e final, como nos exemplos:

"banho" ['bãnu > 'bãyu] "tenho" ['tẽnu > 'tẽyu "maconha" [ma'kõna $>$ ma'kõya] 


\subsection{Ditongação e Monotongação}

\subsubsection{Ditongação}

A ditongação, ao que tudo indica, é um fenômeno essencialmente fonético causado por necessidades eufônicas, não tendo, assim, existência no sistema da língua, mas em sua realização na fala.

A partir disso, está à mercê das variações de todos os tipos, das puramente linguísticas, ligadas ao contexto fonético imediato, anterior ou posterior, à velocidade de elocução, ou tamanho da palavra, por exemplo, às sociolinguísticas, especialmente ao nível ou registro de fala.

Ao definir a ditongação, Xavier e Mateus (s.d.:123) dizem que ela é a:

transformação de uma vogal em ditongo: um segmento vocálico desdobra-se em dois segmentos, isto é, produz-se um processo de diferenciação tímbrica (ou ditongação) no interior de uma semivogal em posição pré ou pós-vocálica.

Ao tratar dos casos de ditongação na língua portuguesa moderna Câmara Jr. (1977:101) diz que:

No português moderno teve-se a ditongação em mais dois casos: 1. vogal tônica em hiato, quando a) média anterior com o desenvolvimento de um ditongo /éy/ [вy] ou /êy/ [ey], indicando na grafia moderna (idéia, veia); b) média posterior fechada com o desenvolvimento de um ditongo /ôw/ não indicado na grafia e inexistente nas zonas dialetais em que houve a monotongação do ditongo /ôw/ - boa - bôwa. 2. dialetalmente, pela vogal tônica final travada por /s/ pósvocálico, com o desenvolvimento dos ditongos de pospositiva /y/, pás, és, fez, sós, flux, cãs, pronunciadas / pays, fêys, sóys, flúys, kay(n)s/. Dá-se então a neutralização da oposição entre ditongo e vogal simples, desaparecendo a distinção, no caso 2 , por exemplo - pás e pais; sós e sóis, flux e fluis, cãs e cães. 


\subsubsection{Monotongação}

Em direção contrária à ditongação, a monotongação é vista como uma redução do ditongo à vogal simples ou pura, por um processo de assimilação completa, no dizer de Xavier e Mateus. Também tem sido estudada dos mais diferentes pontos de vista, ora como uma variação fonética, de facilidade de articulação, ora como uma marca sociolinguística e dialetal.

A monotongação é, segundo Trask (1996: 226): “Qualquer processo fonológico no qual um ditongo é convertido em monotongo".

Câmara Jr.(1977: 170), ao falar sobre monotongação reforça seu caráter puramente fonético ao mostrar que apesar do ditongo ser monotongado, na grafia ele permanece. Em suas palavras, monotongação é:

Mudança fonética que consiste na passagem de um ditongo a uma vogal simples... Para pôr em relevo o fenômeno da monotongação chama-se, muitas vezes, monotongo, à vogal simples resultante, principalmente quando a grafia continua a indicar o ditongo e ele ainda se realiza numa linguagem cuidadosa. Entre nós há, nesse sentido o monotongo ou /ô/, em qualquer caso, e ai /a/, ei /ê/ diante de uma consoante chiante (p)ouca, (b)oca, (c)caixa, como acha, (d)deixa), como fecha.

Para Xavier e Mateus (s.d.: 249) a monotongação é a "Fusão entre dois elementos de um ditongo que assim evolui para vogal. Pode considerarse um caso particular de assimilação completa”.

Jota (1976:212) considera a monotongação um caso de variante diafásica, ligado à linguagem informal e diastrática, ligada ao nível de escolaridade, ao afirmar:

$\mathrm{Na}$ linguagem coloquial brasileira é comuníssima a monotongação de ei, ai e ou: pêxe (peixe); poço (pouco); faxa (faixa), coronés (coronéis). Nas camadas incultas há tipos de monotongação como Oropa por Europa, Estevo, por Estevão. 
Ao analisar material dos falares de Fortaleza e de João Pessoa, colhido nos inquéritos experimentais do Atlas Linguístico do Brasil nessas cidades, percebemos a grande ocorrência de ditongação e, paradoxalmente, de monotongação, em posições onde elas não existem tradicionalmente.

Num primeiro momento, pode-se pensar numa variação diatópica, marcando as regiões cearense, paraibana ou mesmo nordestina. Contudo, ao analisarmos trabalhos semelhantes realizados em outras regiões do país, constatamos a ocorrência dos mesmos fenômenos nessas regiões, donde se pode descartar a hipótese de variante regional.

Percebe-se, ainda, que todos os trabalhos realizados utilizam corpora de linguagem popular, o que marcaria uma variação diastrática e não diatópica.

A dúvida seria, então, em que nível se dá a ditongação e a monotongação e que fatores linguísticos e extralinguísticos são responsáveis por essas variações.

\subsubsection{O uso da ditongação com a semivogal [ y ] no falar de Fortaleza e de João Pessoa}

Para nossa análise partimos dos seguintes parâmetros:

a) tipo de vogal que se ditonga;

b) contexto posterior;

c) tonicidade;

d) extensão da palavra;

e) registro.

A partir desses parâmetros chegamos aos seguintes resultados:

a) Todas as vogais orais: $a, \varepsilon, e, i, \rho, o, u$ e as nasais $\tilde{a}$, $\tilde{e}, \tilde{o}$ ditongam-se no falar de Fortaleza e de João Pessoa, como nos exemplos:

$$
\begin{array}{ll}
\text { /a/ "paz" ['pays ] } & \text { / є / "pés" ['peys ] } \\
\text { /e/ "fez" ['feys] } & \text { /i/ "quis" ['kiys] }
\end{array}
$$




$$
\begin{array}{ll}
\text { /o/ "nós" ['noys] } & \text { /o/ "arroz" [a'hoys] } \\
\text { /u/ "luz" ['luys] } & \text { /ã / "rãs" ['hãys] } \\
\text { /ẽ / "bem" ['bẽys] } & \text { /õ / "bons" ['bõys] }
\end{array}
$$

b) O contexto posterior que determina a ditongação é o dos fonemas / s / e / z / como nos exemplos:

$$
\begin{array}{ll}
\text { "faz" ['fays] } & \text { "mês" ['meys] } \\
\text { "pôs" ['poys] } & \text { "arroz" [a'hoys] }
\end{array}
$$

c) A sílaba tônica é a que facilita a ditongação, como nos exemplos:

$$
\begin{array}{ll}
\text { “rapaz” [ha'pays] } & \text { "bem” ['bẽy] } \\
\text { “estás" [i ' ' tays] } & \text { "francês" [frã'seys] }
\end{array}
$$

d) A extensão da palavra também é outro fator decisivo para a ditongação. Palavras monossilábicas e dissilábicas são as que mais se ditongam, como nos exemplos:

$$
\begin{aligned}
& \text { "três" ['treys] "mês" ['meys] } \\
& \text { "feroz" [ fв' ' soys] "rapaz" [ha'pays] }
\end{aligned}
$$

e) O nível ou registro que mais favorece a ditongação é o coloquial, informal, familiar, mesmo com informantes de melhor escolarização. 


\subsubsection{O uso da monotongação no falar de Fortaleza e de João Pessoa}

Para nossa análise partimos dos seguintes parâmetros:

a) contexto posterior;

b) extensão da palavra;

c) tipo de registro.

Seguindo esses parâmetros vimos que, quanto à monotongação, os falares de Fortaleza e de João pessoa, apresentam as seguintes características:

a) Contexto posterior

Os fonemas consonantais, / $, 3, \mathrm{r} /$ em posição posterior ao ditongo, facilitam sua monotongação, como nos exemplos:

$$
\begin{array}{ll}
\text { "baixa" ['bala ] } & \text { "paixão" [ pa'fãw] } \\
\text { "feijão" [fe'zãw] } & \text { "queijo" ['kezu] } \\
\text { "touro" ['toru] } & \text { "feira" ['fera] }
\end{array}
$$

b) Extensão da palavra

Quanto maior o número de sílabas na palavra, mais a monotongação ocorre, como, nos exemplos:

"brasileira" [ brasi'lesa ] "esteira" [if'tera ]

"aleijado" [ale'zadu ] "apaixonado" [ apa õ 'nadu ]

“manteiga' [ mã̃tega ] "primeiro" [ pri'meru ]

c) Tipo de registro

A partir dos corpora por nós analisados e, apesar dos informantes serem de nível de escolaridade até a $8^{a}$ série do Fundamental, percebemos que esse fator não seria tão relevante quanto ao tipo de registro de 
fala por eles utilizado. Assim, o grau de escolaridade favorece menos a monotongação do que o registro coloquial e informal em que os inquéritos foram feitos.

\section{Conclusão}

As primeiras análises dos corpora analisados mostram as seguintes tendências, que poderão ser confirmadas, ou não, com a análise dos corpora integrais do $\mathrm{ALiB}$, nesses estados ou com corpora diferentes, de falantes das mesmas cidades agora pesquisadas.

\subsection{Conclusões sobre despalatalização, iotização e apagamento dos fonemas $/ \Lambda / \mathrm{e} / \mathrm{n} /$}

No caso da despalatalização, iotização e apagamento dos fonemas $/ \Lambda / \mathrm{e} / \mathrm{n} /$, chegamos às seguintes conclusões:

a) apagamento do /n/ em sílaba posterior à vogal fechada / i / e de final de palavra;

b) no caso do apagamento do /n/ permanece a nasalização final;

c) uma permanência considerável do $/ K /$ e do $/ \mathrm{n} /$ seguidos de quaisquer tipos de vogais;

d) iotização do $/ \Lambda /$ e do $/ \mathrm{n} /$ em sílabas medial e final de palavra.

Pelos exemplos analisados e mostrados, não há um condicionamento fonético para os casos de despalatalização simples, despalatalização seguida de iotização, apagamento ou mesmo permanência do $/ \Lambda /$ e $/ \mathrm{n} /$ uma vez que todos esses fatos podem ocorrer em diferentes posições, precedendo quaisquer vogais.

A partir da leitura de trabalhos semelhantes realizados em outras regiões do país, podemos concluir que o fato ocorre também nos falares de outros estados do Brasil, o que não configuraria uma variação regional, mas uma variação social. 


\subsection{Conclusões sobre a ditongação e monotongação}

Ao iniciarmos este estudo dos falares de Fortaleza e de João Pessoa tínhamos as seguintes hipóteses:

a) a ditongação de vogais puras e a monotongação de ditongos seriam marcas de variantes regionais e sociais relativas ao nível de escolaridade dos informantes e o tipo de registro de fala;

b) aliadas aos fatores diastráticos estariam as variantes fonéticas, puramente linguísticas, de contexto anterior e posterior, tonicidade e extensão da palavra;

A hipótese de variante regional cearense, paraibana ou mesmo nordestina, está totalmente descartada uma vez o que os mesmos fenômenos ocorrem em diferentes regiões do país, comprovados por trabalhos de estudiosos que analisaram esses falares regionais, como o de Amaral (1920), para São Paulo; Monteiro (1933), para o Ceará; Marroquim (1934), para Alagoas e Pernambuco; Teixeira (1938), para Minas Gerais; Paes (1938) para o Rio Grande do Sul; Teixeira (1944), para Goiás; Nascentes (1953), para o Rio de Janeiro; e mais modernamente, Veado (1983), para Minas Gerais; Meneghini (1983) para Ibiriçá - Rio Grande do Sul; Mota (1986), para Sergipe; Paladino Neto (1990), para o Rio de Janeiro; Silva (1994) para o Rio de Janeiro; Paiva (1996) para o Rio de Janeiro; Cabreira (1996), para Curitiba, Florianópolis e Porto Alegre; Silva (1997), para a Paraíba e Araújo (2000) para o Ceará.

Nossa pesquisa confirmou parcialmente a hipótese da variante social, uma vez que se, por um lado, a escolaridade teve pequena importância, por outro, o registro de fala foi decisivo para a ditongação e monotongação. Os resultados confirmaram completamente a hipótese de variante fonética.

Assim, o fenômeno da ditongação e da monotongação nos falares de Fortaleza e de João Pessoa não é diatópico, é parcialmente diastrático e completamente linguístico: fonético por excelência. 


\section{Referências}

AGUIAR, Martins de. Fonética do português do Ceará. Fortaleza: Revista do Instituto do Ceará, tomo LI, anno LI, 1937. p. 271-307.

AGUILERA, Vanderci A. O fonema / $\Lambda$ /: realização fonética, descrição e sua comparação na fala popular paranaense. Anais do III encontro nacional de fonética e fonologia, João Pessoa: 1988.

As proparoxítonas na linguagem popular e rural paranaense. Anais do IX encontro nacional da anpoll - IX. João Pessoa: Linguística, 1995. v. 2.

AMARAL, A. O dialeto caipira. São Paulo: O Livro, 1920.

ARAGÃO, M. do Socorro Silva de. A despalatalização e a iotização no falar paraibano. Congresso internacional da associação brasileira de linguística - I. Salvador: UFBA, 1994. (Resumos).

ARAGÃO, M. do Socorro Silva de. et al. A despalatalização e consequente iotização no falar de Fortaleza. 1996. Jornada de estudos linguísticos do GELNE - XIV. 1996, Natal. UFRN, 30/10 a 01/11. 1996. (Resumos).

ARAGÃO, M. do Socorro Silva de; MENEZES, Cleusa P.B. de. Atlas linguístico da Paraíba. Brasília: CNPq/UFPB, 1984. v. 1-2.

ARAÚJO, A. A. A monotongação na norma culta de Fortaleza. Fortaleza:UFC, 2000. Dissertação (Mestrado)

ARAÚJO, M. F. R. de. Considerações sobre a monotongação do ditongo decrescente [ ey ] no dialeto de Caxias (MA). -Campinas: Revista Letras da PUC, 2000. 19 (1/2) p. 121-137. 
BERGO, Vitório. Pequeno dicionário brasileiro de gramática portuguesa. Rio de Janeiro: Francisco Alves, 1986.

BISOL, Leda. A palatalização e sua estrutura variável. Estudos Linguísticos e Literários UFBA, n. 5. Salvador, 1986. p. 151-162

. O ditongo na perspectiva da fonologia atual. DELTA, 1989. 5/2, p. 185-224.

. O ditongo em português. Boletim da ABRALIN, 1991. n. 11, p. 51-58.

. Ditongos derivados. DELTA, 1994. v. 10, n. especial, p. 123140.

CABREIRA, S.H. A monotongação dos ditongos orais decrescentes em Curitiba, Florianópolis e Porto Alegre. Porto Alegre. PUC/RS. 1996. Dissertação de Mestrado

CÂMARA JR., Joaquim Mattoso. Estrutura da língua portuguesa. Petrópolis: Vozes, 1972.

. Dicionário de linguística e gramática. Petrópolis: Vozes, 1977.

. História e estrutura da língua portuguesa. Rio de Janeiro: Padrão,1979.

CARUSO, Pedro. A iotização do /-LH/ segundo o Atlas prévio dos falares baianos. Alfa, 1983. 27, p. 47-52.

COELHO, Izete Lehamkuhl; NAUMANN, Isaura M.L. 1994. A supressão do [y] no ditongo decrescente [ey] / monotongação. Anais do I encontro nacional sobre língua falada e ensino, Maceió, 1994. p. 199-206. 
CRYSTAL, D. Dicionário de linguística e fonética. Rio de Janeiro: Zahar, 1988.

A first dictionary of linguistics and phonetics. London: André Deutsch, 1980.

DIAS, Josiane da Luz. O apagamento das semivogais nos ditongos decrescentes no dialeto curitibano. Fragmenta (UFPR) 1993. n. 10, p. 59-69.

HARTMANN, R.R.; STORK, F.C. Dictionary of language and linguistics. London: Applied Science Publishers, 1976.

HORA, Dermeval da. Variação linguística no estado da Paraíba: aspectos fonético-fonológicos. In: GROßE, S.; ZIMMERMANN, K. (Eds.) Substandard e mudanças no português do Brasil. Frankfurt am Main, TFM, 1998. p. 315-328.

JOTA, Zélio dos S. Dicionário de linguística. Rio de Janeiro: Presença, 1976.

LEMLE, Miriam. Heterogeneidade dialetal: um apelo à pesquisa. Rio de Janeiro: Tempo Brasileiro, 1975. 53/54, p. 60-94.

MACAMBIRA, J.R. Fonologia do português. Fortaleza: Imprensa Universitária/UFC, 1987.

MADUREIRA, Evelyne D. Difusão lexical e variação fonológica: o fator semântico. Belo Horizonte: Revista de Estudos da Linguagem, ano 6, v.1, p. 5-22. 1997.

MARROQUIM, M. A língua do nordeste: Alagoas e Pernambuco. São Paulo: Companhia Editora Nacional, 1934. 
MATTHEWS, P. The concise Oxford dictionary of linguistics. Oxford: Oxford University Press, 1994.

MENEGHINI, F. M. O fenômeno da monotongação em Ibiaçá. Porto Alegre: - PUC-RS, 1983. Dissertação (Mestrado)

MONTEIRO, C. A linguagem dos cantadores. Rio de Janeiro, 1933. Tese de doutorado

MOTA, J. Variação entre $e$ e $e i$ em Sergipe. Estudos Linguísticos e Literários UFBA, 1986. 5, p. 119-128.

NASCENTES, A. O linguajar carioca. Rio de Janeiro: Simões, 1953.

PAES, E.F. Alguns aspectos da fonética riograndense. Porto Alegre: [s.ed.],

PAIVA, M. da C. de. 1996. A supressão das semivogais nos ditongos decrescentes. In: SILVA, G. M. de O.; SCHERRE, M. M. P.(Orgs.) Padrões sociolinguísticos: análise de fenômenos variáveis do português falado na cidade do Rio de Janeiro. Rio de Janeiro: Tempo Brasileiro, 1938. p. 219-135.

PALADINO NETO, L. Os ditongos do dialeto carioca. Rio de Janeiro, 1990. UFRJ - Dissertação (Mestrado).

RONCARATI, C.N.S. Enfraquecimento das fricativas sonoras. In ARAGÃO, M. do Socorro Silva de; SOARES, Maria Elias (orgs.) O português não-padrão de Fortaleza, aspectos fonológicos, sintáticos e discursivos. Fortaleza, UFC, no prelo, p.76.

SALLES, A. O falar cearense. Fortaleza: Almanach do Estado do Ceará, 1927. p. 86-90. 
SERAINE, Florival. Relações entre níveis de norma na fala atual de Fortaleza. In: SERAINE, Florival. Linguagem e cultura - estudos e ensaios. Fortaleza: Secretaria de Cultura e Desportos, 1985.

SILVA, E. V. da. A monotongação de [ey] e [ay] nos falares fluminenses. Graphos. Universidade Federal da Paraíba, 1997. v. II, n. 1, p. 54-59.

SILVA, F. de S.. O fenômeno da monotongação em João Pessoa. In: Resumos do PRIMEIRO SIMPÓSIO NACIONAL DE ESTUDOS LINGUíSTICOS, João Pessoa: Universidade Federal da Paraíba, 1997. p. $75-80$.

TEIXEIRA, J. A. O falar mineiro. Revista do Arquivo Municipal, 1938. (separata)

. Estudos de dialetologia portuguesa - A linguagem de Goiás. São Paulo: [s.ed.], 1944.

TEYSSIER, P. Histoire de la langue portugaise. Paris: Presses Universitaires de France, 1980.

TRASK, R. L. A dictionary of phonetics and phonology. London/ New York: Routledge, 1996.

VEADO, R.M. Redução de ditongo: uma variável sociolinguística. In: VEADO, R. M.(Org.) Ensaios de Linguística. Cadernos de linguística e teoria da literatura. Belo Horizonte: UFMG, 1983. n. 9, p. 208-229.

XAVIER, M. F.; MATEUS, M.H.M. Dicionário de termos linguísticos. Lisboa: Cosmos, (s.d). v.1. 